\title{
Productive Ambiguity: Fleshing out the Bones in Yolnu Manikay "Song" Performance, and the Australian Art Orchestra's "Crossing Roper Bar"
}

\section{Samuel Curkpatrick}

\section{Introduction}

In the northern reaches of the Australian continent lies a particular rocky region in the south of Arnhem Land, an Aboriginal Land Trust of almost 100,000 square kilometres and the home of the Yolnu people for millennia. ${ }^{1}$ This stone-country region belongs to the wäna-wațanu (land holders) known as the Wägilak, whose family estates centre around the wäna-naraka (bone country) of Dilipidji, the site of a quarry famous for its production of stone spear-heads and knives used in hunting, trade, and warfare well into the twentieth century. The Wägilak clan lived on these hereditary estates around the headwaters of the Walker River until the 1970s, when many of them moved some $150 \mathrm{~km}$ south to live in the present-day township of Ngukurr.

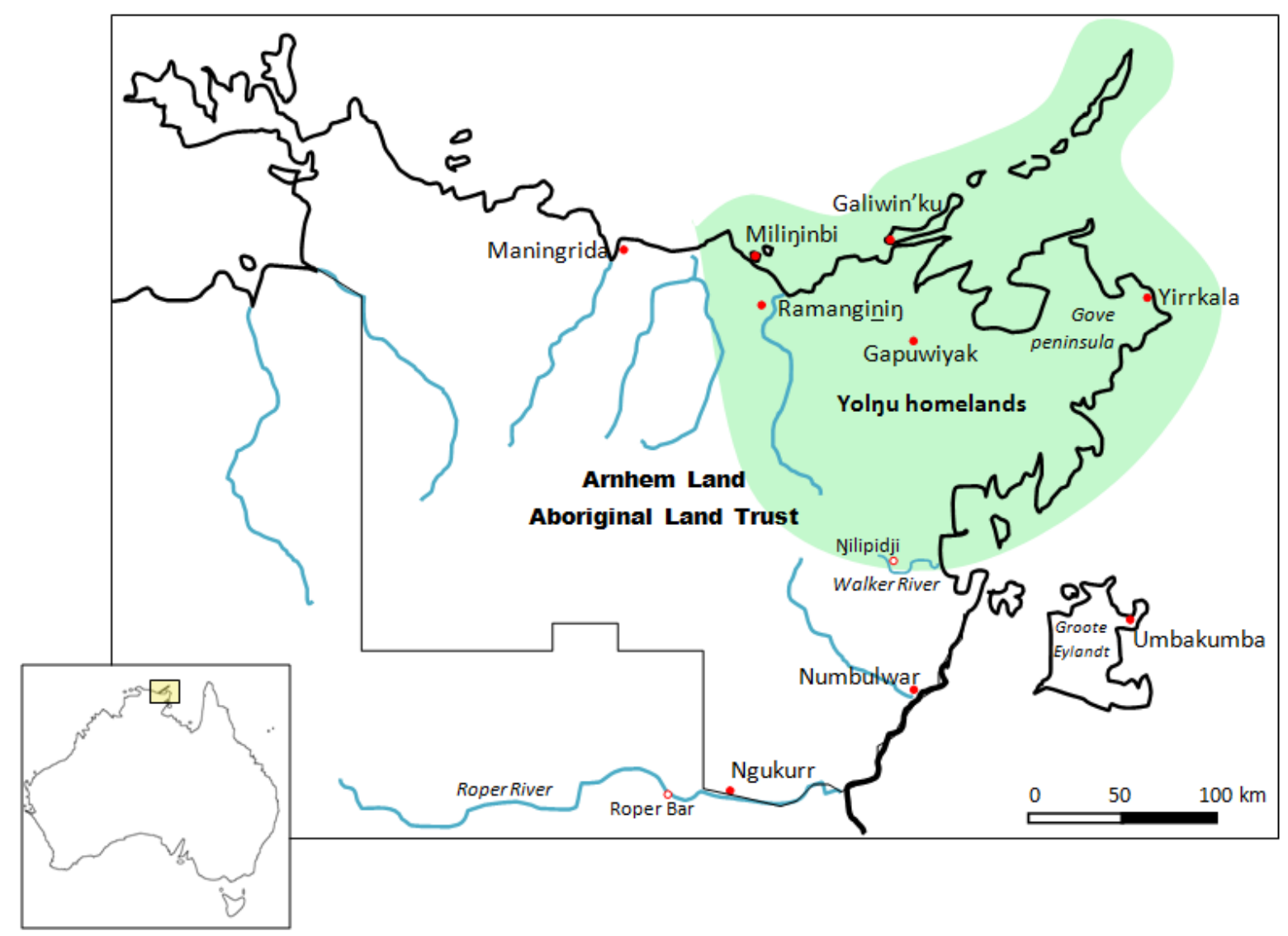

Fig. 1. Map of Arnhem Land showing the Wägilak estate at Dilipidji and present day townships

As a discrete political, social, and linguistic group within the wider Yolnu cultural bloc, the Wägilak clan holds distinct repertoires of manikay (public song), passed down as an orthodox framework perpetuated through the generations and carrying important elements of public law, religion, and narrative. The particular manikay repertoires and narratives belonging to the Wägilak clan offer rich and poetic illuminations of human existence which are simultaneously dense, abstract, philosophic, law-containing, tangibly corporeal, and creatively engaging (see Corn; Corn and Gumbula; Magowan). These vital cultural expressions represent an accumulated wealth of knowledge, passed down through successive generations from origins beyond definitive human agency, and so these traditions are inherently concerned with questions of perpetuation and sustenance. Essentially, manikay is one medium of expression—alongside dance, language, design, and country-employed to sustain engagement with ancestral constitution and presence.

Manikay songs are characterised by their dense heterophonic vocal textures, as anywhere between two and fifteen singers improvises simultaneously around a particular framework of pitch, text, and rhythm, accompanied by complex yidaki (didjeridu) rhythmic patterns and grooving bilma (clapsticks). These melodic lines can be considered improvised because an important aim of musical realisation in manikay remains the unique, vocative 
expression of an individual contributing to the ensemble collective and not the isolated selection of phrases from a stock of possible permutations.

Individuals create powerful performances through their ability to sustain the play of movement within a song, responding to other musicians as they weave their own voice into the whole, in order to hold the orthodox forms of manikay in brilliant, shimmering realisation. A great singer is renowned as one whose improvisations frequently break out of the basic structures of manikay, giving life to the basic forms maintained by the rest of the group. Yet only select elements of manikay demand improvisation, most prominently melodic elaboration coupled with text selection. While the music is replete with productive ambiguities, ${ }^{2}$ these do not, generally, extend to the level of those described by Lewis as characteristic of improvised music in Europe and America after 1950: "the generation of musical structure in real time." In manikay, "salient aspects of a composition" such as song structure, are not "performer-supplied" but ancestrally given (215). This established musical framework emerges as a complex unity above singular, individual creativity.

The ceremonial performance of manikay consists of a sequence of short, repeated song items - up to a minute in length-progressing slowly through a narrative that forms the liturgical program of public ceremonies such as funerals and circumcisions. Each song item concerns a particular subject or theme within the greater narrative, and one such subject from the Wägilak manikay series is "Raki" ("String").

Performed at specific times during week-long funeral rites, the song "Raki" concerns an individual's connection to his or her ongoing generations of family_past, present and future. "Raki" is also a poetic image of an individual's place within the great temporal flow of tradition, understood as the ongoing presence and underpinning precedence of ancestral reality substantiating the present. As an individual occupies a unique place in situations of language, kin, and culture, his or her very being in the present is constituted, nevertheless, by the effective history (Gadamer 299) of the past working on the present. This past continues through the present as yarrata (string-line; agnatic descent), connecting Yolnu today with generations past, and the original creative ancestral action that formed a particular clan's homeland and law (Hamby 211). ${ }^{3}$

Audio example. "Raki," performed by Daniel Wilfred, Benjamin Wilfred, Roy Natilma and David Wilfred (yidaki), 2011.

As well as understanding the past as it works in, around, and through our unique selves, the song "Raki" is an image of the way manikay as an orthodox framework is enlivened through improvisation and creativity. The performance of manikay in ceremony fleshes out the bones of this ancestral framework-carried through the generations in musical form and narrative. Bringing this ancestral text into present relief, improvisation is at the heart of performance as it engages individuals in the process of realising otherwise inert structures through active participation. When "Raki" is performed, the dancer's actions accompanying this item mimic the pounding and then rolling of plant fibres together to make string; a length of string continues to grow as more fibres are entwined into its length. ${ }^{4}$ Similarly, each and every performance of manikay, in whatever time or place it is sung, weaves one more fibre into the great yarrata (string-line) of ancestral continuance, a string that the progenitorial Wägilak ancestor Djuwalpada began weaving long ago. Through performances past, present, and future, a song of complex unity emerges above individual situation and creativity. The performance of manikay today is an integral part of this great existential orientation, connection, and constitution.

Today, the leading songmen of the Wägilak clan are Benjamin and Daniel Wilfred. The bones of what they perform are not new: they continue to weave the string that was sung, danced, and rolled by their father, their father's father, and their father's father's father. This is how knowledge, song, dance, and design are passed down in the Yolnu world. The responsibility to continue to roll and extend the string through the continued performance of your father's ceremonial repertoire is a responsibility to sustain a particular worldview. Narritjin Maymuru, a widely influential Yolnu elder, painter, and singer, suggests:

We can't follow a new way. The new way I cannot do that: I go backwards in order to work. I cannot do any new things because otherwise I might be making up a story-my own thoughts you see-and people over there, wise people, would look at my work and say, "Ah! That's only been made up by him." (qtd. in Morphy 148) 


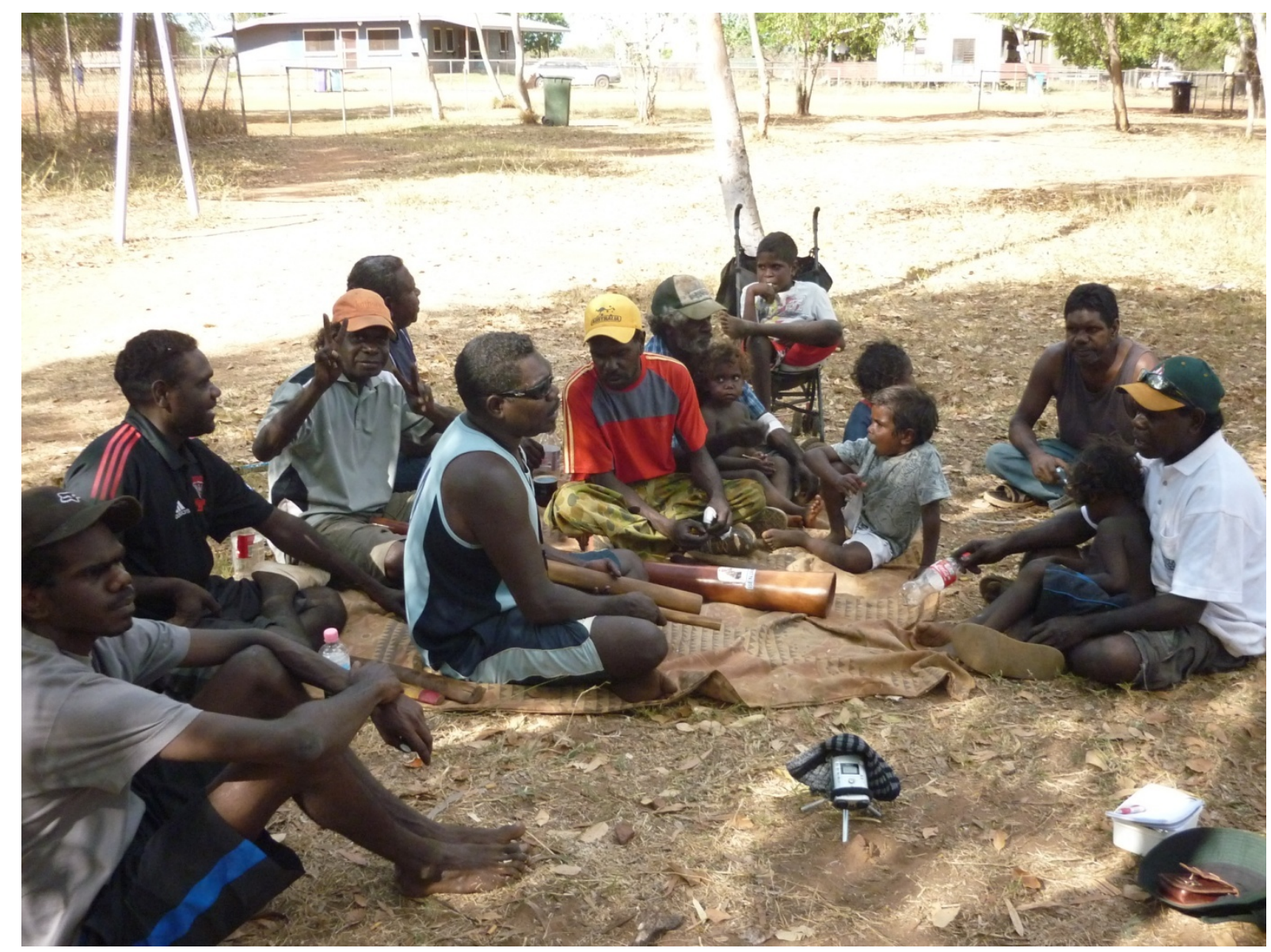

Fig. 2. Wägilak singers performing manikay during funeral preparations, Ngukurr, 2011.

Improvisation always occurs within a prior, established orientation; this is not a contradiction. In the Yolnu worldseen especially in Narritjin Maymuru's wonderful paintings_-interrelated expressions of manikay (song), bungul (dance), and miny'tji (design) are constantly and colourfully reworked with individual creativity. Today, the Young Wägilak Group, a younger generation cohort of Wägilak singers, actively work to engage the present generations with traditional ceremonial practice. Led by Daniel and Benjamin Wilfred, they dramatically envisage manikay through new contexts and media of performance.

Through their engagement with the Australian Art Orchestra, the Young Wägilak Group continue to weave the ancestral raki (string), fleshing out the naraka (bones) of Wägilak manikay with new colours and movement. In this project, known as "Crossing Roper Bar," some of Australia's foremost proponents of contemporary improvisation and leading jazz musicians strive to forge a new manikay that coalesces the manikay of tradition with new contexts and modes of expression-the instruments, musical ideas, sounds, perceptions, responses, and histories - that unique individuals bring to the engagement. The result is dynamic, engaging music that is always shifting in iteration, never stagnating but speaking into each and every context of performance.

Fundamentally, the collectively improvised music avoids appropriation through culturally illegitimate reification.

Listening example. "Birrkpirrk" (Plover) from "Crossing Roper Bar" album, 2010.

In one sense, "Crossing Roper Bar" is a demonstration of Yolnu ingenuity in the perpetuation of orthodox cultural forms and ideas, and a celebration of the great indigenous performance traditions of this land. It is also a groundbreaking experiment in the role of creativity in cross-cultural engagement, flowing discursively through multiple iterations that seek to constantly shift horizons of understanding. Ultimately, "Crossing Roper Bar" is one fibril strand actively intertwined by individuals today into the great, ongoing ancestral raki (string).

\section{The blueprint of Wägilak manikay}

Manikay is for country, for leading the new generation. Manikay is for using in funeral, wata ["wind"], smoking [purification ceremony]. Learn about country. Manikay means spirit for the country, and songs; where he walked, the Wild Blackfella [ancestral ghost] called Djuwalpada. (Benjamin Wilfred in Curkpatrick et al.) 
As we sit around the campfire, Benjamin Wilfred tells a story. He tells us the story of the ancestral ghost Djuwalpada; he tells us about manikay and its importance, for the country, for the people, and for the future. This is how learning takes place in the Yolnu world, through storytelling in narrative, song, dance, or painting. Fragments emerge out of the darkness and a complex picture slowly begins to build. Over the years, a constellation of tales, poetic images, names, sounds, and movements combine together into a densely textured whole. While understanding the richness of manikay is a lifelong pursuit, persistent narrative tenets pervade all performances.

Wägilak manikay begins with a journey: Djuwalpada, the ancestral mokuy (ghost) of the Wägilak people, began walking through the land, looking for a home. The land was wild and dangerous, and Djuwalpada was frightened. With his elbows pointed, he looked high in the treetops of the gardayka (stringybark trees), searching for some guku (honey). Following the sugarbag (bees) and the dhangarra (stringybark flowers), he succeeded. The honey was good, and dancing he sung: hey, gu gu gu gu, gey gey! He put the honey in his dillybag (woven basket; lawbag) and kept on searching for a home.

Djuwalapada holds his spear, getting ready to throw. The spear will show him where to go, where his home is. The moment builds and the spear breaks away. It flies; its path is struck and it enters the ground. Wägilak law is, now and here. This is their place; their path is struck. This is stone spear county, called Dilipidji.

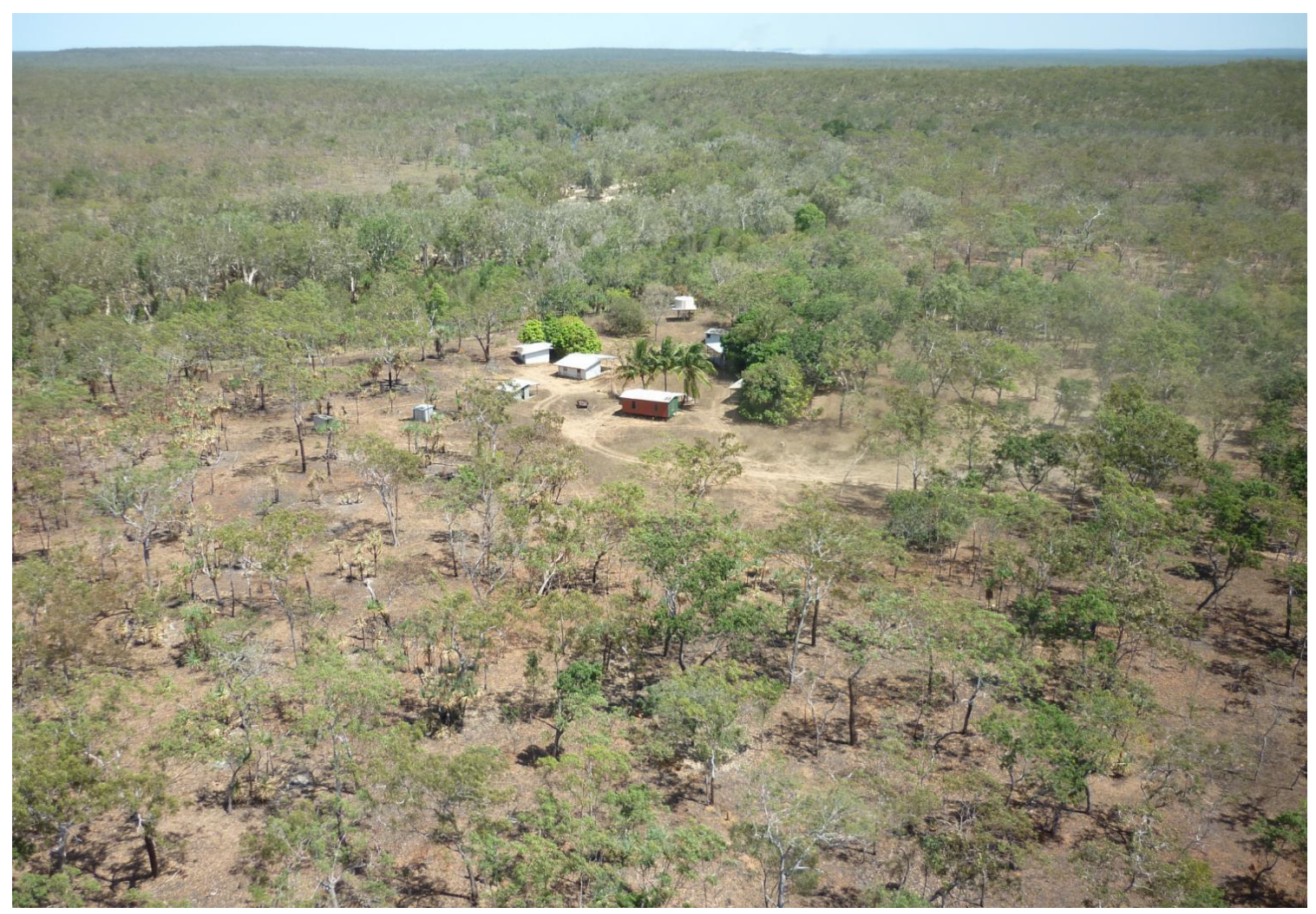

Fig. 3. The Wägilak outstation at Dilipidji, stone-spear country.

The journey of Djuwalpada sets in motion the narrative at the heart of the Wägilak manikay repertoire, and the subjects of each song progress through this story in the following order: Djuwalpada (Wägilak ghost), Gara (Spear), Galpu (Spear thrower), Galpan (Woven basket), Raki (String), Mälka (String bag), Birrkpirrk (Lap-winged plover), Wata (Wind). Only a basic version of this story has been outlined above. In the Yolnu world, this story is bursting with an excess of poetic and narrative significations, philosophic observations, and complex interactions with different clan narratives and countries. ${ }^{5}$

The musical forms in manikay support the retelling of this basic narrative. In each particular manikay subject ("Raki," "Mälka" etc.) there is a progression of bilma (clapstick) patterns, encoding the narrative action in rhythmic mode. "Djuwalpada," the first subject in the Wägilak narrative, is initially accompanied by the "walking mode"associated with Djuwalpada walking through the countryside naming plants and animals throughout the entire song series. The accompanying dance actions are performed in synchronicity with this repetitive rhythmic structure, translating sound into movement, form into corporeal expression, and bringing narrative action into being. The following table shows a few of the Wägilak bilma modes as they animate the beginning of 
Djuwalpada's journey. For each song subject, there is a fixed sequence of rhythmic modes that must be followed in all performances.

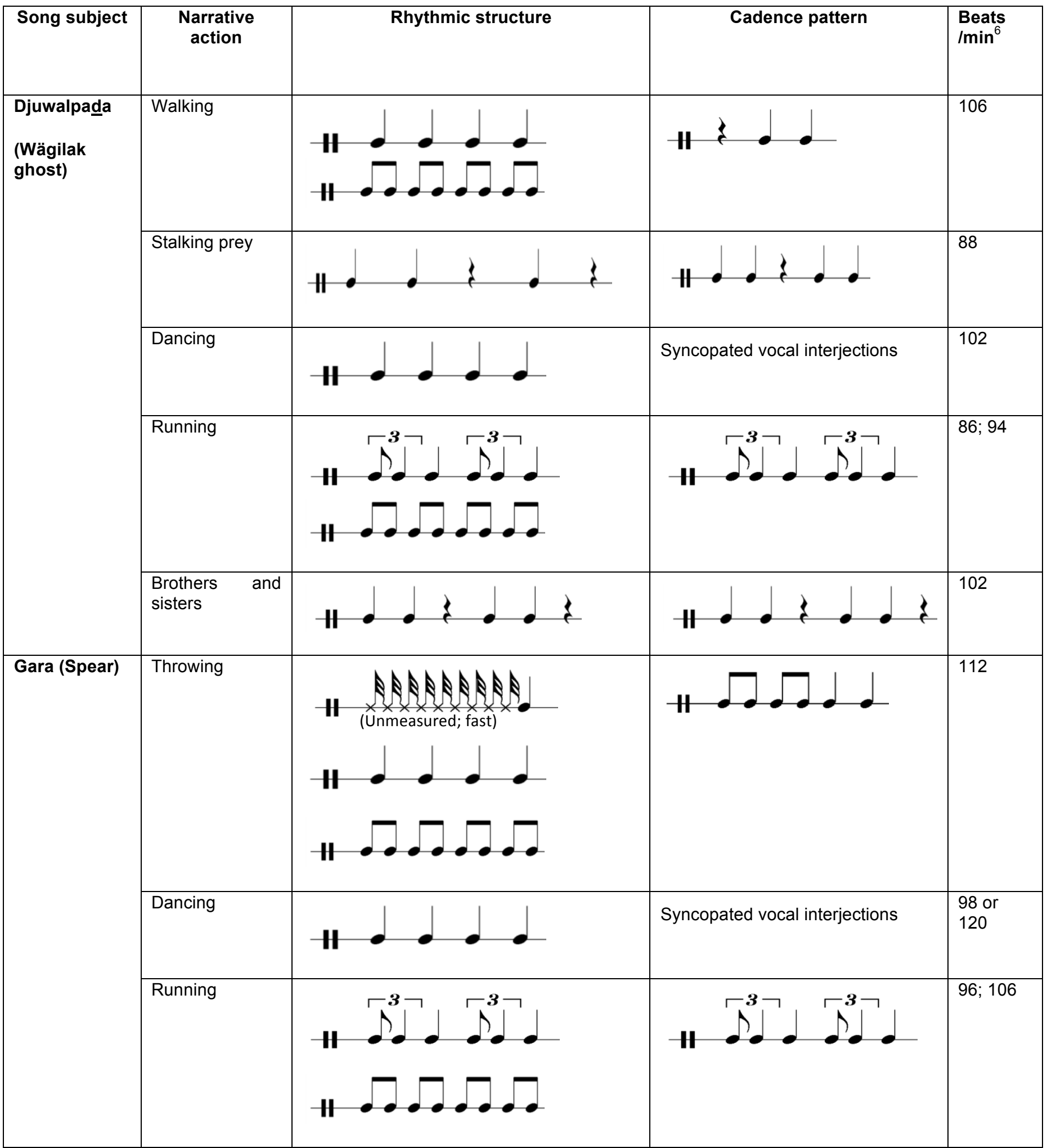

Fig. 4. Table of Wägilak billma modes for the song subjects "Djuwalpada” (Wägilak ghost) and “Gara” (Spear).

Bilma (clapstick) modes are integral naraka (bones), structuring the orthodox framework of manikay. They must always be performed in the correct sequence, no matter what the performance context. As singer Daniel Wilfred asserts, "everything comes out of the clapping sticks. All the song today, the clapping sticks lead all of them" (D. 
Wilfred). Where these rhythmic patterns are changed, a yuta manikay (new song) is created and then incorporated into the established manikay series (such as "Brothers and Sisters" above).

Importantly, clans connected through ringitj (embassy) associations and obligations share the same bilma modes, pervasive throughout their otherwise distinct manikay (song) and bungul (dance) repertoires. These modes are at the heart of social and ceremonial connections between clans perpetuated through the generations; the rhythmic naraka (bones) of manikay grasp after stability. Here, musical forms are tied inseparably to important legal interests, family groupings, country ownership, and hereditary rights and responsibilities. As in all Yolnu ceremony, "at the core there is a persistent emphasis on conformity to pattern" (Morphy and Morphy 69).

Rhythmic bilma (clapstick) modes do, however, incorporate a degree of productive ambiguity that describes the productive space allowed by a governing structure for individual choice, improvisation, and elaboration; space that permits the free play of movement ever renewing the work of art as novel event (498). Productive ambiguity engages performance, drawing singers into the creative realisation of the orthodox text, which becomes known in the present through active participation.

Improvising on this basic bilma groove is the yidaki (didjeridu), bound by the terminal cadence pattern of each song item." These virtuosic improvisations carry the dancers with momentum and syncopation. There is only one yidaki player in every performance of manikay and each individual brings their own approach to elaborating or filling out the basic rhythmic bones of a song, elaborating the rhythmic-narrative structure with complexity created through a combination of vocables, timbre changes, and overtones "hoots." Every yidaki player has his or her own characteristic style.

Audio example. David Wilfred demonstrating yidaki patterns over the basic rhythmic mode for "Dancing" song items (see above table of bilma modes).

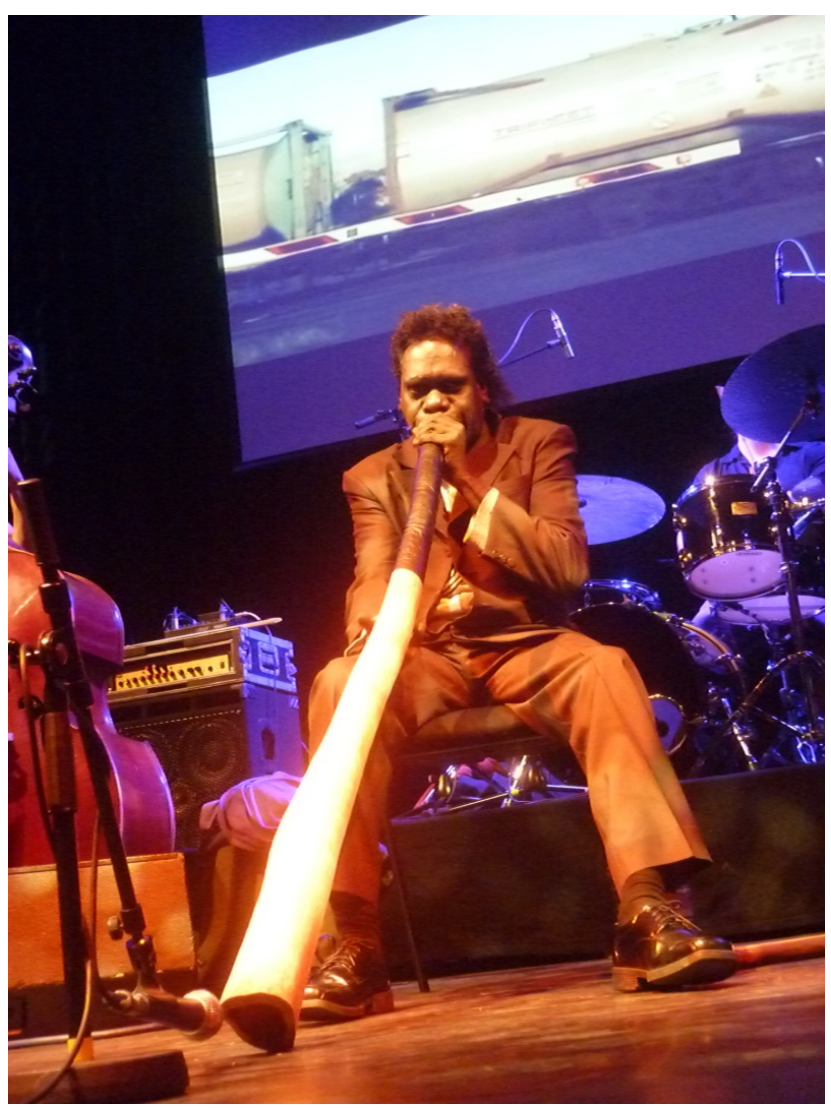

Fig. 5. David Wilfred playing yidaki (didjeridu), London Jazz Festival, 2012.

Each set of manikay songs is also based on the particular melodic and harmonic patterns specific to an individual clan. There are dozens of clans in Arnhem Land and each uses a unique dämbu (head), a term that refers to the pitch structure of a clan's entire song series. ${ }^{8}$ Voices improvise independently around the dämbu in a melismatic cascade of sound, weaving words and phrases that poetically describe the narrative action (refer to first listening example). The dämbu begins high and falls downwards through a basic pitch series over the course of a gumurr (chest) segment. 
Importantly, the dämbu (head) is not just realised by independent voices, as a singer sets text to pitch. The overall ensemble is characterised by the dense harmony created as these voices combine. The $\underline{d}$ ämbu is fixed relative to the starting pitch from which it descends: no matter what pitch the song begins on-and it can begin wherever the lead singer chooses-the intervallic structure remains the same. While this starting pitch may shift over the course of a performance, often moving higher towards the climax of a ceremony, the span of the intervals remains consistent (Toner 72). Represented as a scale, the dämbu unique to the Wägilak clan approximates to the following. ${ }^{9}$

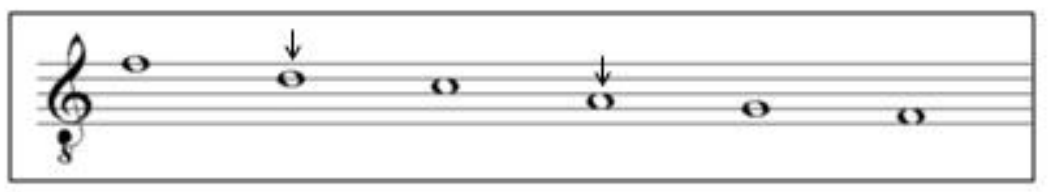

Fig. 6. The Wägilak dämbu (head).

Dämbu is a clan's musical signature and the entire Wägilak manikay series is bound by this intervallic construction, even as divergence is permitted. This integral melodic naraka (bone) of ceremony is instantly recognisable to those educated in Yolnu ceremony. Hearing a song item performed-hearing a familiar $\underline{\text { dämbu- }}$ leads to direct recognition of the particular hereditary estate and narrative to which those songs belong. Alongside the characteristic bilma (clapstick) modes belonging to a clan's manikay series, dämbu is an orthodox element perpetuated through all performances in whatever context or manifestation they may occur. By singing manikay with regard to its orthodox pitch structures, ancestral laws regarding estate ownership and kinship relations between closely related clans and homelands are sustained. Benjamin Wilfred explains: "So you have to hold your culture strong like me: for the future, for the next generation. We are the Young Wägilak Group now, and we are holding that manikay and bungul ['dance']. Hold it real strong" (qtd. in Curkpatrick et al.).

The simple, figurative form of $\underline{d} a ̈ m b u$ also embraces productive ambiguity: the very performance of manikay

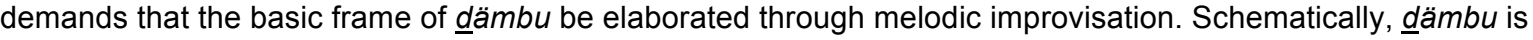
a "fairly static intervallic structure" (Corn 8), yet in performance it becomes a rich tapestry of musical relationships. Individual lines weave around each other, merging into a musical form that mirrors the density of ceremonial signification and suggests an indigenous phenomenology of unity amid complexity. The surface of this thick vocal texture shimmers with brilliance and märr (strength; spiritual power), and strong voices emerge over the top, reaching for pitches outside of this framework or transposed into the octave above the starting pitch. Powerful performance is created by extending the song into a virtuosic liya-waya (coda), keeping the song strong, singing with strong voice.

Listening example. Refer back to previous example, "Raki," to hear improvised voices and an extended a liyawana (coda).

Reiteration of a tradition or musical form is contingent on variation, and the possibility for variation is contingent on reiteration: "The Yolngu concept of tradition admits the actuality of individual variation, and innovation as a proof of its continuing vitality and authenticity, passed from leader to leader through the successive generations" (Caruana and Lendon 26). This is reflected in the forms of manikay and can be seen at work in the improvisations of the yidaki (didjeridu) around bilma modes, and singers around the dämbu pitch sequence. Improvisation around these basic forms fleshes out the inbuilt ambiguities within the orthodox framework of manikay, filling out the figurative narrative of Djuwalpada with a brilliance of colour, variety, ingenuity, and possibility. Creative improvisation allows the forms of manikay to be disclosed through active, situated expressions in performance, and individuals participate in life as nalabulupu rom, an integral "following" of ancestral precedent, law, and correct practise (Curkpatrick, Old Masters).

Similar instances of creative musical expression integral to the perpetuation of tradition have been explored in Hebrew synagogue songs (Kim 40). However, publications in this field generally focus on conscious stylistic innovations rather than the real-time animation of orthodox forms through improvisation. Discussion of such innovation is predominantly held in the terminology of continuity and change, similar to McClary's understanding of innovation as a paradigmatic oscillation between "convention" and "counter-convention" (McClary 3 ).

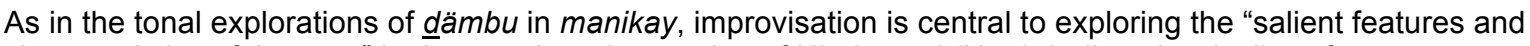
characteristics of the raga" in the opening alap section of Hindustani (North Indian classical) performance (Paranjape 2). Here, improvisation allows the creativity of the individual performer to generate ongoing musical conversation and engagement with traditional tonal structures: "Any improvisation in Indian music is of value only insofar as it advances the aesthetic impact of the rāga [...] made manifest through improvised performance" (Slawek 335). Napier also argues a similar view of Hindustani music, but prefers the terminology of "representation" or "reconfiguration" rather than improvisation; my own preference for the term is an appraisal of 
the unique voices of individuals, outlined above, and also follows Ross' exploration of improvisation as real-time "tactical decision making" (3).

Manikay is ever the "same but different," an individual re-articulation of orthodox tenets combining into shimmering, collective improvisation. Even as performers apply their unique creativity to the orthodox forms of manikay, filling-in the productive ambiguities within a set musical framework-spaces of volition and independence-they are nevertheless caught in the interminable conversation of tradition. Tradition in and around us is engaged through the animation of creative reiteration, resonating with Gadamer's notion that in the performance of art, "the player experiences the game [of participation] as a reality that surpasses him" (98). Individual performances of manikay-single fibril strands woven into a greater ancestral orientation-continually disclose the underpinning tenets and profound ideas constituting Yolnu existence and experience.

\section{“Crossing Roper Bar"-a new manikay}

We can't change it. When you listen to those songs from Wild Blackfella [Djuwalpada]; all one. We can't change it. Law: that's Wägilak Law. (B. Wilfred)

"Crossing Roper Bar" is a laudable approach to musical engagement amid diversity in Australia, a performed conversation between individuals in contemporary Australian contexts and the Wägilak manikay tradition. Despite the orthodox Yolnu hermeneutic explored above, this project is embraced as culturally legitimate-it maintains the integral naraka (bones) or musical frameworks central to the perpetuation of ancestral law and narrative through song.

Since 2005, the collaboration has resulted in performances and workshops across Australia, from dusty outdoor bungul (dance and entertainment) in the remote Aboriginal community of Ngukurr, to the Sydney Opera House. In 2012, "Crossing Roper Bar" extended its reach to Europe with a tour including performances at Cambridge University, the London Jazz Festival, and at the Quai Branly Museum in Paris. ${ }^{10}$ Wherever it is performed, "Crossing Roper Bar" illuminates manikay as a vital tradition engaged with the present, known through dramatically envisioned iterations within ever expanding contexts of performance.

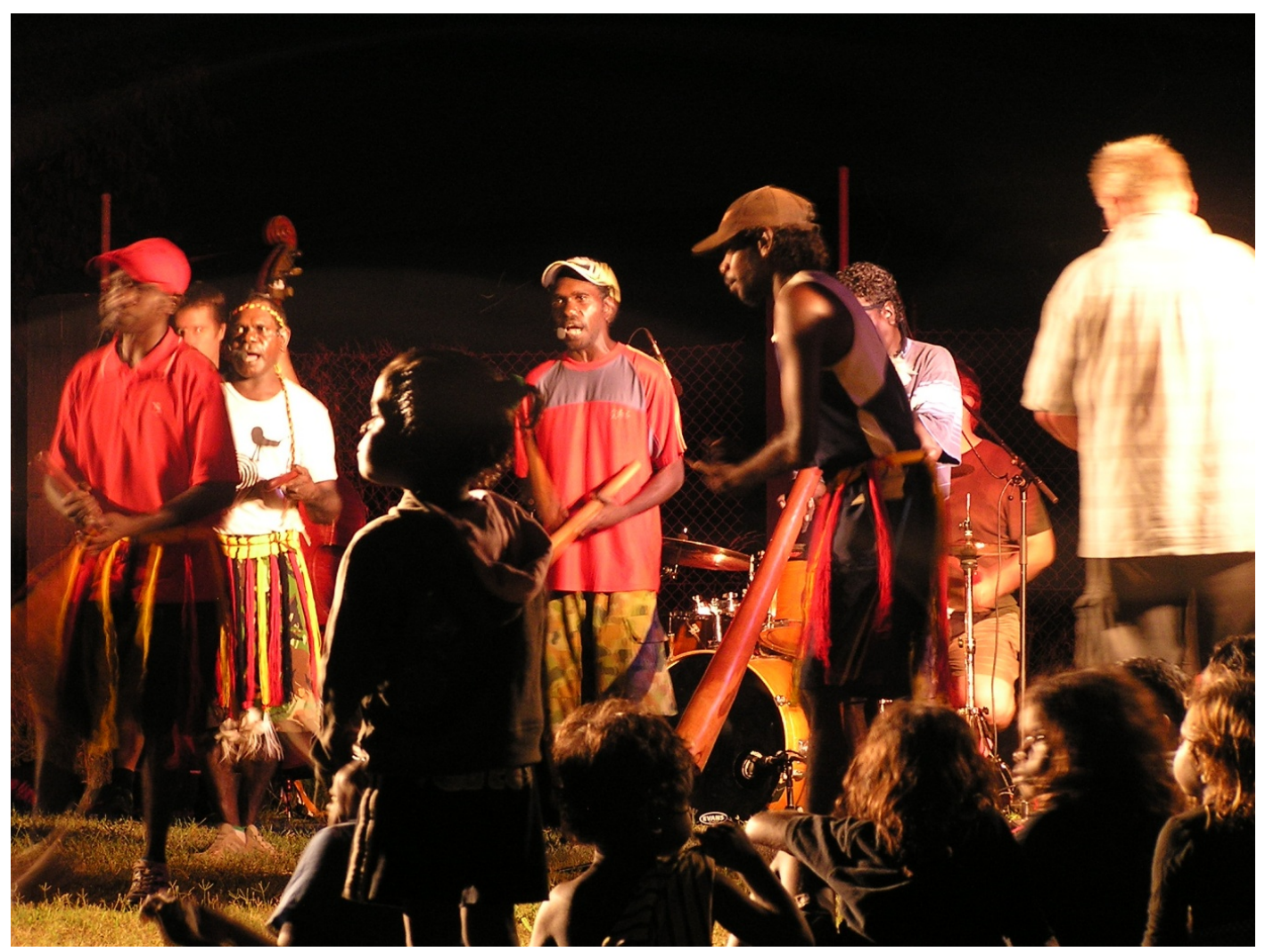

Fig. 7. “Crossing Roper Bar” in concert, Ngukurr, 2010. 


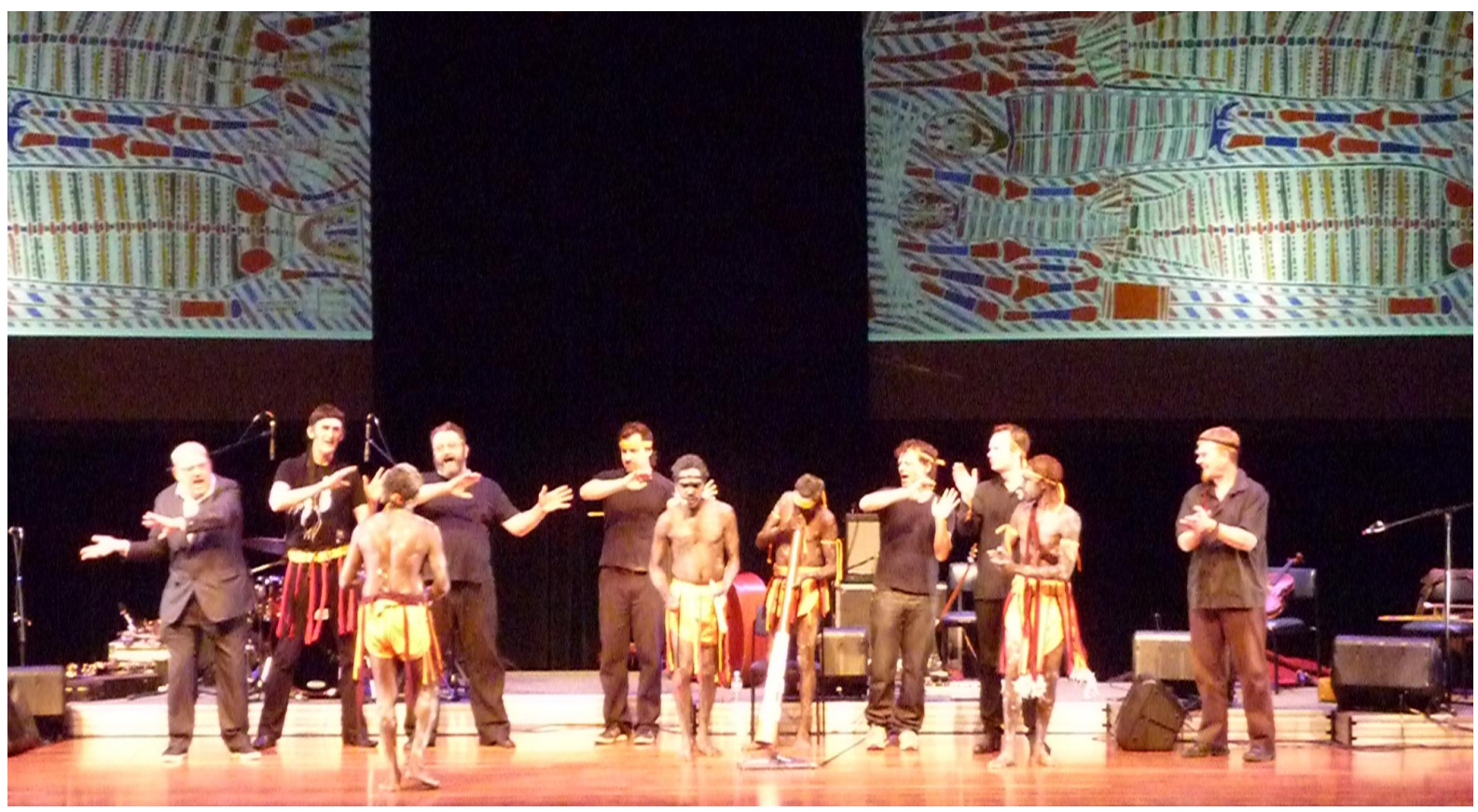

Fig. 8. "Crossing Roper Bar" in concert, Canberra, 2010.

The music of "Crossing Roper Bar" is based predominantly on the improvisations of all musicians gravitating around the performance of a public Wägilak manikay series, specifically the liturgical program for smoking and purification ceremonies. Directed by pianist Paul Grabowsky, the usual line-up of Balanda (whitefella) musicians over the past few years has consisted of Tony Hicks (winds), Niko Schäuble (drums), Erkki Veltheim (violin/viola), Steve Magnusson (guitar), and Philip Rex (double bass). As a result, performances are always shifting within and between iterations of performance as new ideas and sounds emerge, multimedia elements are incorporated, yuta manikay (new songs) are composed, and knowledge about the song series and musical intricacies of manikay grow. "Crossing Roper Bar" is a dynamic collaboration of real-time performed conversation with orthodox ancestral forms.

The free improvisations of the AAO resonate with the ambiguities built into the orthodox framework of Wägilak manikay, especially as "the exact repeatability of sounds tends to clash [...] with the idea of the essential uniqueness of the moment that forms part of the jazz attitude" (Pressing 3). Yet while the music and ideas within the project are always on the move-in a discursive, exploratory sense, avoiding illegitimate appropriation through definitive reification-the sentiments expressed by artistic director Grabowsky during the orchestra's first trip to Ngukurr, in 2005, remain: "What I'm hoping is that we'll together be able to create a work over time in which we are equals, which is a reflection and a record of the specific situation [of engagement and encounter]" (Australia Broadcasting Commission).

Here, improvisation is a tool for drawing people together, creating a sense of being present in a contemporary social, political, and historical reality-to "reclaim and re-perform history" in the sense that Caines explores in research into Australian hip hop workshops with Indigenous youth (1). As in local manikay contexts, improvised performance perpetuates an awareness of life within coordinates of substantiating, effective history: individual voice begins from a context of situation. Similarly, Lewis' writing also moves to reinstate the place of memory and history as integral components orienting improvised music, especially within African-American experiences (23233).

For the Young Wägilak Group—Benjamin, Daniel, and David Wilfred—who lead the Australian Art Orchestra (AAO) in the performance of manikay, "Crossing Roper Bar" offers a unique possibility for asserting the value and ongoing viability of Wägilak traditions within the greater, mainstream Australian public, whose awareness of Yolnu culture, law, and history is scant if extant. For the improvising musicians of the AAO, "Crossing Roper Bar" is an attempt to form a dynamic and respectful engagement with some Indigenous Australian musicians, whose rich and valuable cultural expressions have been largely ignored by Australian music, musicians, and culture in general. On the whole, the collaboration offers the possibility for creating a truly unique form of Australian music that belongs to this land and people. Here, creativity is central to generative, productive engagement with culture, especially across temporal and social distances (Fischlin and Heble 1-42; Hallam and Ingold 3-9; Stanyek 112).

The AAO's collaboration with musicians from Ngukurr has been, from the very beginning, premised on a foundation of listening "with wide open ears and minds" (Schäuble). This is a fundamental acknowledgement that 
Yolnu traditions possess valuable richness and depth beyond the immediate grasp of outsider's ears and minds. In desiring to understand more about Wägilak manikay, and by extension Yolnu law and culture, the AAO do not approach this musical tradition as a trove of otherness to be plundered: dialogue (musical and interpersonal) is not closed off in definitive, immutable representation, and the collaboration's agenda remains the development of greater understanding across cultural differences through shifting musical iterations. The Wägilak tradition remains something actively performed, challenging individual's conceptions of music as much as it inspires. In the same way that Yolnu ceremony brings people together in the act of sharing, celebrating, and connecting, the process of engagement in "Crossing Roper Bar" as a collaboration is much more important than the creation of distinct or distinguished outcomes. ${ }^{11}$

Gadamer's exploration of hermeneutics resonates with this performed encounter between subjectivities and cultures: "To reach an understanding in a dialogue is not merely a matter of putting oneself forward and successfully asserting one's own point of view, but being transformed in a communion in which we do not remain what we were" (371). This approach accepts that one's particular horizons of understanding are situated and, as such, open to shift-an important agenda driving "Crossing Roper Bar." From the very first trip to Ngukurr in 2005, the musicians of the AAO sat down on the ground and listened to the Wägilak musicians, learning about manikay through their participation in dance, storytelling, and most importantly building relationships with people and place. All improvisations begin from this foundation.

During a presentation at the Australian National Academy of Music, musical director of "Crossing Roper Bar" Paul Grabowsky reflected on the necessary basis of active, engaged listening, something that underpins the AAO's projects. These involve collaborating with individuals and cultural traditions from Australia, India, Japan, and Indonesia: ${ }^{12}$

\begin{abstract}
So there is in listening [as one improvises] an active component and a passive one simultaneously, in the sense that you are receiving information, and immediately feeding it back into the conversation in order to move it forward [...] Because improvisers have learned the value of a courageous approach to their instruments, in that they always search for new ways to do things and new avenues for self expression, they have been in my experience especially good at using music to bridge cultural divides. (Grabowsky "Art Orchestra")
\end{abstract}

As musicians schooled in the art of listening with great nuance of perception, the AAO are able to improvise a new, spontaneous creation in every performance of "Crossing Roper Bar" that nevertheless centres on the orthodox elements of the Wägilak manikay series: every performance is "the same but different." As in jazz improvisation, the music coalesces around manikay as a "notion of agreement"-the structures around which improvisation unfolds-even where these structures are "internalised and experienced implicitly" (Alterhaug 109).

In "Crossing Roper Bar," the Young Wägilak Group perform a sequence of manikay songs that form the liturgical program for a smoking/purification ceremony, in which the presence of the mokuy (ghost) Djuwalpada is sent back to his home at Dilipidji. At the climax of this ceremony, the song "Wata" ("Wind") is sung. The rhythmic modes slowly build, generating momentum and energy as the wind picks up, blowing the mokuy (ghost) home. Here, the basic bilma patterns-which carry the narrative action and dance-become a point of convergence for the AAO. These patterns give the AAO the possibility of creating a groove that underpins improvisations and connects individuals across cultural distance.

Daniel Wilfred frequently reminds the orchestra, "those clapping sticks, they are the main ones. Follow those clapping sticks." On this rhythmic foundation, improvisations build layers of complexity much like the yidaki (didjeridu), which animates the basic rhythmic modes with complex layers of invention, energy, and syncopation.

Listening example. Persistent rhythmic foundation ("Stalking prey" bilma mode) in "Galpu" (Spear thrower) from "Crossing Roper Bar" album, 2010.

The orthodox forms and sequences of the bilma (clapsticks) are given momentum in performance, transiting from abstract conception into experienced phenomena and kinaesthetic sympathy. Here, musical form is a beginning of cohesion, completed only in the iteration of performance. The AAO's sensitivity as they engage with rhythmic elaborations of Wägilak bilma modes suggests a coincidence of expression amid complex diversity. While maintaining characteristics integral to the framework of Wägilak manikay, they engage with these forms from their own situations of creativity, filling in basic grooves with improvised complexity, realising these forms from their own subjectivities as unique musicians.

In "Crossing Roper Bar," improvisations also extend from the blueprint of the Wägilak dämbu (head), and musicians characteristically weave new vocal lines_on their respective instruments-into the established tonality and texture of manikay. As each manikay song-item ends, the space allowed by the liya-wana (coda) becomes 
the ground for further exploratory improvisation, appropriately sustaining the märr (ancestral power) of a song by extending the length of a song item.

The following example of an improvised liya-wana (coda) in "Crossing Roper Bar" is taken from the song "Gara." Following the cadence that concludes this manikay song-item, Erkki Veltheim (viola) performs an exploratory alteration of intervals shifting around the basic framework of the dämbu (head), much like the improvisation of a manikay singer. Rather than a detailed transcription, the notated example below shows the intervallic structure of this improvisation as it weaves in and out of Tony Hicks' (tenor saxophone) improvised line; bar lines are inserted for visual clarity. In a sense, this coda could be considered bi-tonal, as Veltheim explores the intervals of the dämbu around the pitch of $\mathrm{G}$, Hicks around the pitch of F\#. The resulting texture and tonal ambiguity is a very beautiful moment that befits the manikay style.

Listening example. Improvised liya-wana (coda) by Tony Hicks and Erkki Veltheim. "Gara" (Spear), from "Crossing Roper Bar" album, 2010.

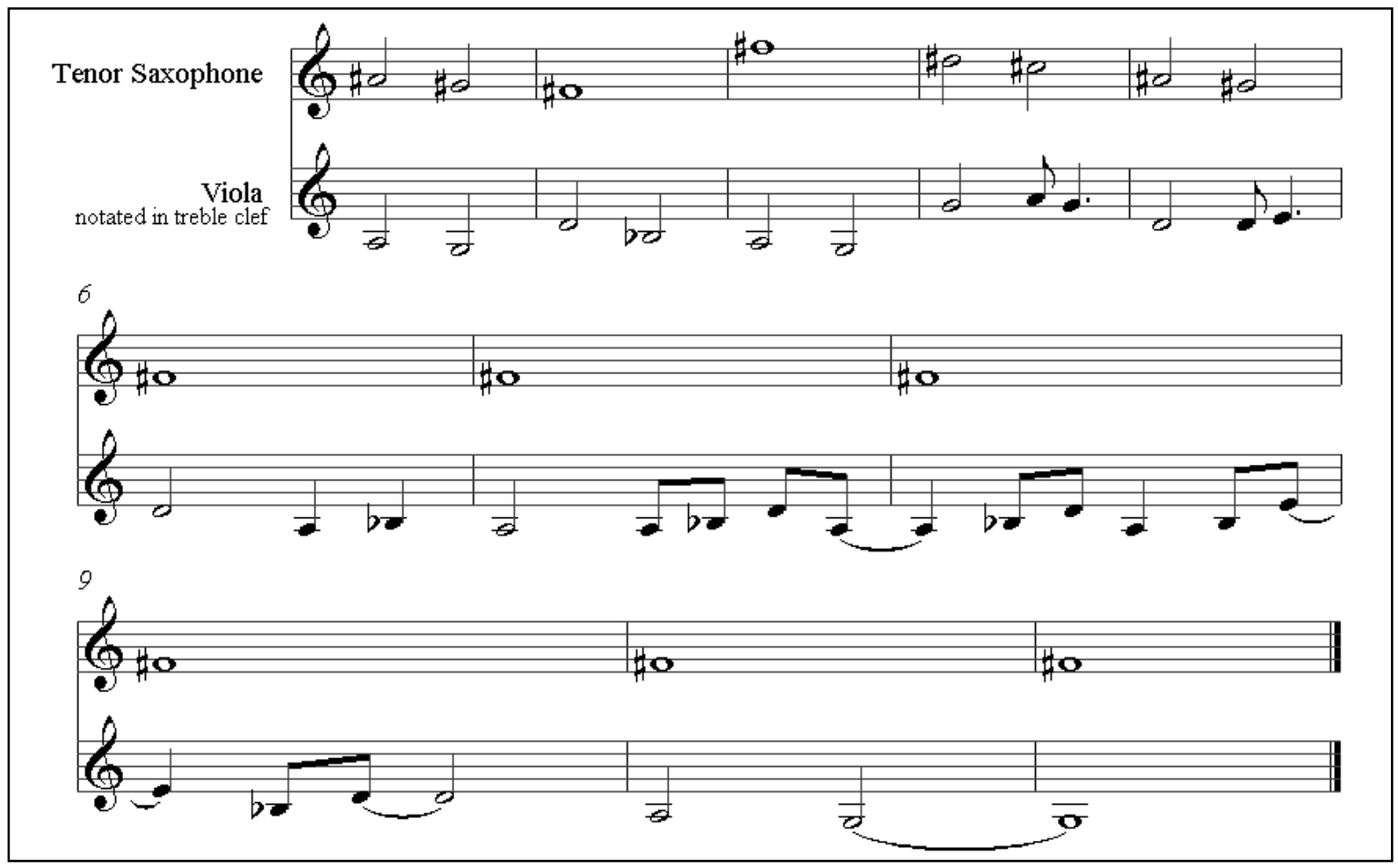

Fig. 9. Pitch transcription of improvised liya-wana (coda) from "Birrkpirrk" (Plover).

The AAO maintain characteristics integral to the orthodox framework of Wägilak manikay, such as the basic forms and sequences of bilma modes, and the characteristic Wägilak dämbu. In doing so, they engage with these structures from their own situations of creativity, filling in basic grooves with improvised complexity and weaving new and distinct melodic lines into the overall texture. Even as new iterations of "Crossing Roper Bar" are realised, an ongoing and shared experience of the forms of manikay tradition are carried into the present. This movement of realising and giving voice to an orthodox text-and the important significations, narratives and ancestral law that it carries-is central to the manikay tradition. As performers flesh out the bones of manikay, filling in the productive ambiguities inherent in the framework with improvisation and creativity, each individual is addressed by the reality of ancestral precedence (effective history) underpinning contemporary performanceeven if they understand and respond to this address in their own unique way:

We can learn much from our first nations, but perhaps the most important thing is that sense of unity of people and place, space and time, expressed through the creative act: that we are one, not rhetorically but in fact, and that this oldest of knowledge should inform our better selves. (Grabowsky, "Art is a River")

We're the Young Wägilak Group now, with my story, with my grandpa's story, and the spirit of grandpa following me. Giving me power, strong power. That's why l'm talking strong. And I love my tour ["Crossing Roper Bar"], what I do [...] I'm lucky l'm holding this Wägilak culture strong. I'm standing here and talking for country, and I'm walking with spirit, with Wild Blackfella called Djuwalpada. Even when I tour with the 
orchestra, that Wild Blackfella [follows], no matter where I go [...] And I'm here; a strong man. (Benjamin Wilfred)

\section{Conclusion}

Productive ambiguities built into the orthodox framework of manikay allow Yolnu social and legal traditions to engage the present generation through realisation in performance, where individual creativity fleshes out the orthodox bones of musical structure through improvisation. Similarly, "Crossing Roper Bar" is a coming together as in ceremony, engaging individuals across cultures, situations, generations, and history, perpetuating the fundamental blueprint of Wägilak manikay in new contexts.

Key formal structures of bilma and dämbu underpin this engagement, fleshed out with unique voice, drama and colour: the ever-shifting iterations of improvisation permit musicians the freedom to converse creatively with other individuals and traditions. Through performance, something emerges which is beyond the individual, or the individual collective (ensemble), and yet the individual is central to this emergence: "In performances of improvised music, the possibility of internalizing alternative value systems is implicit from the start. The focus of musical discourse suddenly shifts from the individual, autonomous creator to the collective" (Lewis 234).

Creativity and improvisation permits a living engagement with manikay as a relevant text of tradition. While the blueprint of manikay exists like the ancestral raki (string), above the individual fibres or iterations of each performance, manikay is nevertheless disclosed through performances within the particular perspectives offered by context and musical utterance. As an orthodox text, Wägilak manikay "is potential before it is actualized. It is capable of being formed though it is not yet formed" (Gadamer 423), reified in existence and present as a pervasive force beyond the time of an individual's life span.

Yet in the actualisation of its iteration, in the experience of is corporeal expression, manikay is renewed. Yolnu and Balanda understanding of ancestral underpinnings emerges from progressive revelation in ever-widening possibilities and contexts of performance. This reality is embraced by manikay and the "Crossing Roper Bar" collaboration, as tradition dramatically engages with contemporary perspectives. The manikay tradition continues to shape individuals' understandings of one another, and our place in society, culture, and history:

All art is latent until the moment it is received by the viewer, listener or reader, at which point it ignites, catching fire in the atmosphere of the mind [...] A work is never the same twice: no matter how many times we encounter it, our experience is dependent on circumstance. (Grabowsky, "Art is a River")

The sustenance of the manikay tradition is contingent upon creative application, and improvisation is at the heart of continued, discursive engagement with cultural forms of others or the past. Even as a unique and present collective emerges from the individuals improvising and performing manikay song, "Crossing Roper Bar" becomes, simultaneously, one iteration within the established, ongoing raki (string); one voice woven into a dense, heterophonic texture; one improvised realisation amid a history of performance; one fibre intertwined into the ongoing, ancestral song.

\section{Notes}

${ }^{1}$ Note on orthography and pronunciation:

$\mathrm{D}$ or $\mathrm{n} \quad$ Capital and lowercase; pronounced like "ng" as in song.

ä Long "a" as in far.

d Retroflex consonant; " $d$ " with the tongue curled back, touching the roof of the mouth.

2 "Productive ambiguity" is a term borrowed from German philosopher Hans-Georg Gadamer, referring to the renewing play of movement held within structural frameworks. This play allows a work of art continually to become a new event (498).

${ }^{3}$ As an expression of particular estate ownership and family connection, improvisation in songs like "Raki," do not seek freedoms from conventions that contribute to a new, pan-Aboriginal musical identity, as in Stanyek's PanAfrican improvisation (89). Rather, they sustain localised and relatively autonomous identities. These identities are maintained within wider society and ever-opening contexts of engagement.

${ }^{4}$ Traditional uses of raki (string) include the manufacture of bags, mats, fishing line, and rope. Raki also has many important ceremonial uses and significances, and can be woven into law-bags (or dillybags, a symbol of political authority), adorned with parrot feathers and used in exchange ceremonies.

\footnotetext{
${ }^{5}$ For a detailed exploration of the Wägilak manikay narratives, see Curkpatrick's "Conversing Tradition."
} 
${ }^{6}$ Crotchet beats per minute. Even though the musical forms of manikay are passed down as a largely aural tradition, bilma modes remain amazingly consistent through the generations when measured in beats per minute.

${ }^{7}$ Especially in eastern Arnhem Land where the Wägilak homelands are located, the didjeridu is primarily a rhythmic instrument rather than a tonal one. However, the didjeridu does provide a tonal reference point for singers in western Arnhem Land, in song styles such as kun-borrk (Djimarr).

${ }^{8}$ For more detailed explanations see Corn; Corn and Gumbula; Knopoff.

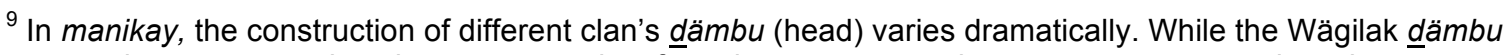
seems almost pentatonic, others may consist of tonal spans greater than an octave or even less than $\bar{a}$ tone. A dämbu may include only two distinct pitches or any other number to around six or seven.

${ }^{10}$ This performance can be viewed on the website, http://liveweb.arte.tv/fr/video/Crossing Roper Bar musee du quai Branly/

\footnotetext{
${ }^{11}$ A similar approach to collaboration in Australia is the efforts of Genevieve Campbell and the Wangatunga Strong Women's Group from the Tiwi Islands. This group re-cognise historic song styles with western instrumental accompaniment, reinvigorating community interest in cultural activities, and spawning interest in further investigating old, archived recordings and documentation. As Campbell suggests, "It's not a type of exotic or ethno-defined music. Tiwi music is vital and relevant. It is, after all, Australian contemporary music." The project centres on participation, creation and re-invention: "Perfect performance-that's not what we're aiming for and there's no such thing anyway" (Campbell et al.).

${ }^{12}$ The various projects of the Australian Art Orchestra are based on an ethos of expanding assumptions and knowledge of music through collaboration; see http://www.aao.com.au.
}

\section{Works Cited}

Alterhaug, Bjørn. "Improvisation on a Triple Theme: Creativity, Jazz Improvisation and Communication." Studia Musicologica Norvegica 30 (2004): 97-118. Print.

Australian Broadcasting Commission. "Orchestra Collaborations with Top End Musicians." Program Transcript: The 7.30 Report. Murray McLaughlin (reporter). ABC, 2005. 21 June 2011. Web. 20 Aug. 2011. http://www.abc.net.au/7.30/content/2005/s1428683.htm.

Australian Art Orchestra. Crossing Roper Bar. North Melbourne, 2010. Audio.

Caines, Rebecca. "Giving Back Time: Improvisation in Australian Hip-Hop Pedagogy and Performance." Critical Studies in Improvisation 6.2 (2010): 1-19. Web. 6 Aug. 2013. http://www.criticalimprov.com/article/view/1264/1931.

Campbell, Genevieve, and the Wangatunga Strong Women's Group. Ngarukuruwala: We Sing Songs. Nguiu: Stolen Planet Productions, 2008. Audio.

Caruana, Wally and Nigel Lendon, eds. The Painters of the Wagilag Sisters Story 1937-1997. Canberra: National Gallery of Australia, 1997. Print.

Corn, Aaron D. S. "Ancestral, Corporeal, Corporate: Traditional Yolnu Understandings of the Body Explored." Borderlands 7.2 (2008): 1-17. Web. 20 Aug. 2011. http://www.borderlands.net.au/vol7no2 2008/corn ancestral.pdf

Corn, Aaron D. S, and Neparrna Gumbula. "Rom and the Academy Repositioned." Boundary Writing: An Exploration of Race, Culture and Gender Binaries in Contemporary Australia. Ed. Lynette Russell. Honolulu: U of Hawaii P, 2006. 170-97. Print.

Curkpatrick, Samuel. "Conversing Tradition: Wägilak Manikay 'Song' and the Australian Art Orchestra's 'Crossing Roper Bar."” Diss. Australian National U, 2013. Print.

---. "Old Masters: Creative Articulations of an Ancestral Text." ReCollections 8.1 (2013). Web. 6 Aug. 2013. http://recollections.nma.gov.au/issues/volume 8 number $1 /$ commentary/old-masters. 
Curkpatrick, Samuel, Benjamin Wilfred, Daniel [Desmond] Wilfred, and Justin Nunngarrgalug. "Digital Audio Technologies and Aural Organicism in the Australian Art Orchestra's 'Crossing Roper Bar."' Australian Institute of Aboriginal and Torres Strait Islander Studies Conference. Canberra, Australia. 14 July 2010. Paper Presentation and Discussion.

Djimarr, Kevin. Wurrurrumi Kun-Borrk: Songs from Western Arnhem Land. Field Recording and Production by Murray Garde and Stephen Wild. Sydney: Sydney UP, 2007. Audio.

Fischlin, Daniel and Ajay Heble, eds. The Other Side of Nowhere: Jazz, Improvisation, and Communities in Dialogue. Middletown: Wesleyan UP, 2004. Print.

Gadamer, Hans-Georg. Truth and Method. London: Continuum, 2006. Print.

Grabowsky, Paul. "Art Orchestra, ANAM and Arnhem Land." Australian National Academy of Music. South Melbourne, Australia. 15 Apr. 2011. Paper Presentation.

---."Comment: Art is a River.” The Monthly. Oct. 2012. Web. 5 Jan. 2013. http://www.themonthly.com.au/issue/2012/october/1349327288/paul-grabowsky/comment-art-river.

Hallam, Elizabeth and Tim Ingold, eds. Creativity and Cultural Improvisation. Oxford: Berg, 2007. Print.

Hamby, Louise. "Wrapt with String.” Textile 5.2 (2007): 206-229. Print.

Kim, Patrica Costa. "Transmission of Music in the Hebrew Tradition: Learning from the Songs of the Synagogue." The Bulletin of Historical Research in Music Education 19.1 (1997): 40-51. Print.

Knopoff, Steven. "Yolngu Clansong Scalar Structures." The Garland Encyclopedia of World Music, Australia and the Pacific Islands. Vol. 9. Ed. Adrienne L. Kaeppler and J.W. Love. New York: Garland Publishing, 1998: 141. Print.

Magowan, Fiona. Melodies of Mourning: Music and Emotion in Northern Australia. Oxford: James Currey, 2007. Print.

McClary, Susan. Conventional Wisdom: The Content of Musical Form. Berkeley: U of California P, 2000. Print.

Morphy, Howard. Becoming Art: Exploring Cross Cultural Categories. Sydney: U of New South Wales P, 2008. Print.

Morphy, Howard and Frances Morphy. "Tasting the Waters: Discriminating Identities in the Waters of Blue Mud Bay." Journal of Material Culture 11.1 (2006): 67-85. Print.

Napier, John. "Novelty That Must Be Subtle: Continuity, Innovation and 'Improvisation' in North Indian Music." Critical Studies in Improvisation 1.3 (2006): 1-17. Web. 6 Aug. 2013. http://www.criticalimprov.com/article/view/55/105.

Paranjape, Wasanti. "Khyal, Improvisation, and Social Change." Critical Studies in Improvisation 8.1 (2012): 1-6. Web. 6 Aug. 2013. http://www.criticalimprov.com/article/view/1994/2655.

Pressing, Jeff. "Free Jazz and the Avant-garde." The Cambridge Companion to Jazz. Ed. Mervyn Cooke and David Horne. Cambridge: Cambridge UP, 2002. 202-216. Cambridge Collections Online. Web. 7 Aug. 2013. http://universitypublishingonline.org/cambridge/companions/ebook.jsf?bid=CBO9781139002233.

Ross, David. "Activating Bodies of Knowledge: Improvisation, Cognition and Sports Education." Critical Studies in Improvisation 7.2 (2011): 1-5. Web. 6 Aug. 2013.

Schäuble, Niko. Personal Interview. 13 Oct. 2011.

Slawek, Stephen. "Keeping it Going: Terms, Practices, and Processes of Improvisation in Hindustani Instrumental Music." In the Course of Performance: Studies in the World of Musical Improvisation. Ed. Bruno Nettl and Melinda Russell. Chicago: U of Chicago P, 1998. 335-68. Print. 
Stanyek, Jason. "Transmissions of an Interculture: Pan-African Jazz and Intercultural Improvisation." The Other Side of Nowhere: Jazz, Improvisation, and Communities in Dialogue. Middletown: Wesleyan UP, 2004. 87-130. Print.

Toner, Peter. "Melody and the Musical Articulation of Yolngu Identity." Yearbook for Traditional Music 35 (2003): 69-95. Print.

Wilfred, Benjamin. Personal Interview. 21 July 2010.

Wilfred, Daniel. Personal Interview. 6 Mar. 2011. 